\title{
A Resolução de Problemas no ensino de
} Cálculo Diferencial e Integral nos Cursos de Engenharia: uma experiência

\author{
The Problem Solving in Differential and Integral Calculus \\ Education in Engineering Courses: an experience
}

Diego Monteiro Gomes ${ }^{1}$, Nilson Sergio Peres Stahl ${ }^{2}$

\begin{abstract}
RESUMO
O artigo apresenta um trabalho realizado utilizando-se da Resolução de Problemas (RP), preconizada por George Polya, para o ensino de Cálculo Diferencial e Integral aos alunos de cursos de Engenharia (Computação, Produção e Mecânica). Nosso objetivo principal foi compreender de que forma a Metodologia de Resolução de Problemas pode contribuir para o aprendizado de Cálculo Diferencial e Integral. Foram realizadas duas atividades contendo situações-problema contextualizadas com temas da Engenharia a fim de promover um ensino significativo na disciplina. A experiência aqui relatada foi desenvolvida com um total de 31 estudantes matriculados na disciplina Cálculo 1 ofertada por duas instituições de ensino superior em Campos dos Goytacazes, RJ. Optamos por uma abordagem qualitativa, utilizandose na coleta de dados de questionários com perguntas abertas respondidas pelos educandos. Os resultados apontaram importantes benefícios promovidos pelo uso da Metodologia de Resolução de Problemas ao ensino de Cálculo como: trabalho colaborativo, conteúdo contextualizado, facilitação do aprendizado, entre outros.
\end{abstract}

Palavras-chave: Resolução de problemas; cálculo; engenharia; ensino-aprendizagem.

\section{ABSTRACT}

The article presents a work carried out using the Problem Solving (PS), recommended by George Polya, for teaching Differential and Integral Calculus to students of Engineering courses (Computing, Production and Mechanics). Our main objective was to understand how the Problem Solving Methodology can contribute to the learning of Differential and Integral Calculus. Two activities were carried out containing problem situations contextualized with Engineering themes in order to promote meaningful teaching in the discipline. The experience reported here was developed with a total of 31 students enrolled in the subject Calculus 1 offered by two higher education institutions in Campos dos Goytacazes, RJ. We opted for a qualitative approach, using the data collection of questionnaires with open questions answered by students. The results pointed out important benefits promoted by the use of the Problem Solving Methodology in the teaching of Calculus, such as: collaborative work, contextualized content, facilitating learning, among others.

Keywords: Problem solving; calculation; engineering; teaching-learning.

\footnotetext{
${ }^{1}$ Universidade Estadual do Norte Fluminense - UENF, Campos dos Goytacazes/RJ - Brasil. E-mail: diegomonteirogomes@gmail.com

${ }^{2}$ Idem. E-mail: nilson8080@gmail.com
} 


\section{INTRODUÇÃO}

O ensino superior tem sido amplamente discutido nos últimos anos em pesquisas e eventos ligados à educação no Brasil. Entre os tópicos discutidos encontram-se os conteúdos de aprendizagem aplicados nos cursos de graduação e as metodologias de ensino que vêm sendo empregadas na tentativa de aprimorar a formação do profissional de Engenharia. (FERREIRA; SILVA; NUNES, 2015; ARANHA; SANTOS, 2016; WATANABE et al., 2018).

Nesse cenário, o ensino da disciplina Cálculo Diferencial e Integral (CDI) desponta como um dos principais desafios. Pesquisas apontam altos níveis de reprovação dos estudantes na disciplina ministrada nas instituições nacionais e indicam uma formação deficiente dos egressos. (LOURENÇO et al., 2014; STARON, 2016). Como apontou o Exame Nacional de Desempenho de Estudantes (ENADE), aplicado aos graduandos em 2014:

O baixo percentual de respostas consideradas medianas e boas, bem como a elevada incidência de notas zero atribuídas a essa questão revelam uma grave lacuna na formação dos estudantes, representada pelo escasso conhecimento acerca de conteúdos curriculares transmitidos no âmbito da disciplina Cálculo Diferencial e Integral, básica de qualquer curso de Engenharia. (INEP, 2016, p.79).

Parte dos pesquisadores em educação matemática atribui o problema à metodologia tradicional de ensino que induz uma postura não crítica nos estudantes, pouca participação, e a não compreensão dos conceitos devido a não contextualização do ensino. (PINTO; LIMA, 2017; SOUZA; FONSECA, 2017; PAULA; SOARES; DIAS, 2016). Nesse contexto, esse artigo apresenta uma experiência no ensino de Cálculo Diferencial e Integral (CDI) em cursos de Engenharia utilizando a Metodologia de ensino de Resolução de Problemas (RP), preconizada pelo matemático George Polya. Este trabalho é um recorte de uma pesquisa de mestrado na qual trabalhamos com um total de 31 alunos oriundos de duas turmas regulares de Cálculo Diferencial e Integral. Os participantes são estudantes de Engenharia Mecânica, Engenharia de Produção e Engenharia da Computação de duas instituições de ensino superior em Campos dos Goytacazes - RJ.

A fim de construir significados e conhecimentos matemáticos sobre o conceito de derivação e taxa de variação, foram elaboradas duas situações-problema com a finalidade de proporcionar aos educandos um aprendizado com significado e contextualizado desses conceitos de Cálculo Diferencial e Integral (CDI).

O presente estudo buscar compreender como a Metodologia de ensino de Resolução de Problemas pode contribuir para a construção do conhecimento dos alunos na disciplina de Cálculo Diferencial e Integral, segundo a percepção dos mesmos.

\section{METOdOLOGIA DE ENSINO DE RESOLUÇÃO DE PROBLEMAS}

A Resolução de Problemas no âmbito da aprendizagem data de tempos remotos, desde a Grécia antiga. Mas foi sistematizada e teve sua aplicabilidade amplamente difundida a partir do trabalho do matemático George Polya em 1945 com o 
lançamento de seu livro intitulado "How To Solve It - a new aspect of Mathematical Methods". A obra de Polya foi traduzida para o português como "A Arte de Resolver Problemas", sendo a $1^{\circ}$ edição pulicada em 1986 no Brasil. (POLYA, 1945; ONUCHIC; ALLEVATO, 2011).

A partir de então, como proposta pedagógica a Resolução de Problemas (RP) ganhou diferentes perspectivas na educação matemática. Ribeiro (2010) e Abdelmalack (2011) apresentam três modos de abordagem da Resolução de Problemas que ganharam destaque no meio acadêmico: ensinar sobre Resolução de Problemas, ensinar Matemática para Resolução de Problemas e ensinar Matemática por meio da Resolução de Problemas. Os autores definem as diferentes propostas da seguinte forma:

Ensinar sobre Resolução de Problemas - abordagem que possui um enfoque no ensino dos procedimentos de resolução. Nessa perspectiva, o aluno deveria dominar as estratégias e o passo a passo para resolver os problemas. O objetivo do professor era que o aluno dominasse a técnica de resolução independente do assunto tratado. Entretanto, percebia-se que o domínio dos procedimentos e técnicas não garantia o entendimento dos conceitos matemáticos e a sua aplicação no momento oportuno.

Ensinar Matemática para Resolução de Problemas - Nessa concepção, o foco é realizar aplicações matemáticas dos conteúdos já vistos. Assim, primeiramente ocorre o ensino de um conteúdo ou conceito matemático e posteriormente, a resolução dos problemas em si. A principal crítica contra essa abordagem é por favorecer uma concepção simplista na qual a Resolução de Problemas serviria apenas para contextualizar ou dar um emprego prático a um conteúdo ou conceito já ensinado.

Ensinar Matemática por meio da Resolução de Problemas - a terceira perspectiva entende a RP como um caminho possível para ensinar matemática, tendo o aluno no papel central na construção do conhecimento. Nessa concepção, o professor utiliza um problema gerador para ensinar um conteúdo ou um conceito matemático. Assim, busca propiciar ao aluno um pensar matemático, um comportamento de investigação, contando ainda com os benefícios das outras duas abordagens, como a contextualização e o aprendizado dos procedimentos de resolução.

Adotamos em nossa pesquisa a proposta de ensinar Matemática por meio da Resolução de Problemas. Entendemos tratar-se da perspectiva mais adequada diante das necessidades de mudança no ensino de CDI.

\subsection{ROTEIRO DE APLICAÇÃO DA METODOLOGIA DE RESOLUÇÃO DE PROBLEMAS}

Em sua obra, Polya (2006) traça um roteiro para professores e alunos. Aos professores, apresenta a Resolução de Problemas como proposta pedagógica. Aos alunos, aponta como um caminho para solução dos problemas matemáticos. A Tabela 1 apresenta as etapas, objetivos e características de cada fase de aplicação da RP: 
Tabela 1 - Etapas e ações a serem desenvolvidas pelos professores e alunos na Metodologia de Resolução de Problemas de Polya.

\begin{tabular}{|c|c|c|c|}
\hline Fases & Ações do professor & Ações do Aluno & Objetivo da fase \\
\hline $\begin{array}{l}\text { Compreensão do } \\
\text { problema }\end{array}$ & $\begin{array}{l}\text { Apresentar o } \\
\text { problema; Despertar } \\
\text { o interesse do aluno; }\end{array}$ & $\begin{array}{l}\text { Entender o problema; } \\
\text { Identificar as } \\
\text { incógnitas, os dados, } \\
\text { a condicionante; }\end{array}$ & $\begin{array}{l}\text { Promover o } \\
\text { entendimento e o } \\
\text { engajamento do aluno }\end{array}$ \\
\hline $\begin{array}{l}\text { Elaboração de um } \\
\text { plano }\end{array}$ & $\begin{array}{l}\text { Propiciar, } \\
\text { discretamente, ideias } \\
\text { aos alunos para } \\
\text { produção de um } \\
\text { plano; Indagar e } \\
\text { sugestionar para } \\
\text { provocar ideias; }\end{array}$ & $\begin{array}{l}\text { Encontrar a conexão } \\
\text { entre os dados e a } \\
\text { incógnita; Raciocinar } \\
\text { de forma lógica e } \\
\text { objetiva; Elaborar um } \\
\text { plano de resolução } \\
\text { do problema; }\end{array}$ & $\begin{array}{l}\text { Estimular o raciocínio } \\
\text { lógico do aluno; } \\
\text { Despertar } \\
\text { conhecimentos } \\
\text { anteriores e correlatos } \\
\text { ao problema. }\end{array}$ \\
\hline Execução do plano & $\begin{array}{l}\text { Auxiliar os alunos na } \\
\text { execução do plano; } \\
\text { Garantir que eles } \\
\text { sigam e verifiquem } \\
\text { os passos } \\
\text { anteriormente } \\
\text { propostos; }\end{array}$ & $\begin{array}{l}\text { Executar o plano } \\
\text { previamente } \\
\text { estabelecido; } \\
\text { Verificar se cada } \\
\text { passo seguido está } \\
\text { correto; }\end{array}$ & $\begin{array}{l}\text { Aplicar os conceitos } \\
\text { matemáticos, efetuar } \\
\text { os cálculos. }\end{array}$ \\
\hline $\begin{array}{l}\text { Retrospecto do } \\
\text { problema }\end{array}$ & $\begin{array}{l}\text { Verificar, junto com } \\
\text { os alunos, todo o } \\
\text { problema, o plano e } \\
\text { os passos seguidos } \\
\text { para resolução e o } \\
\text { resultados. }\end{array}$ & $\begin{array}{l}\text { Examinar a solução } \\
\text { obtida; Verificar com } \\
\text { o professor desde o } \\
\text { problema proposto } \\
\text { até resolução } \\
\text { completa. }\end{array}$ & $\begin{array}{l}\text { Consolidar o } \\
\text { conhecimento e } \\
\text { aperfeiçoar a } \\
\text { capacidade de } \\
\text { resolução de problemas }\end{array}$ \\
\hline
\end{tabular}

Fonte: Elaborada pelos autores.

Diante de sua aplicabilidade e relevância, a Metodologia tem sido abordada em teses e dissertações com importantes contribuições desenvolvidas no Brasil pelo Grupo de Estudos em Resolução de Problemas (GTERP) localizado na Universidade Estadual Paulista. O GTERP mediante o desenvolvimento de estudos e investigações em ensinoaprendizagem de matemática por meio da RP elaborou e aprimorou um roteiro de ensino. Ribeiro (2010) apresenta, em seu trabalho com alunos de cursos de Engenharia na disciplina de Cálculo, o roteiro aprimorado composto das seguintes etapas:

Preparação do problema - O professor escolhe um problema gerador visando construir junto com os alunos um novo conceito da disciplina;

Leitura individual do problema pelos alunos - Cada aluno recebe uma cópia do problema para leitura individual;

Leitura em grupos do problema - São formados grupos e uma nova leitura em conjunto é feita pelo grupo de estudantes; 
Resolução do problema - Os grupos formados procedem com a tentativa de resolver os problemas, trocando ideias entre si e trabalhando de forma colaborativa;

Observação e incentivo - O professor atua como tutor guiando, observando e estimulando a cooperação entre os membros do grupo.

Registro das resoluções na lousa - Um representante de cada grupo é convidado a compartilhar na lousa a resolução utilizada pelo seu grupo, independente de estar certa ou errada;

Plenária - O professor promove uma discussão com os estudantes sobre as diferentes resoluções encontradas.

Busca de consenso - Após sanar as dúvidas e analisadas as diferentes soluções, o professor busca estabelecer um consenso sobre o resultado certo;

Formalização do conteúdo - Nessa etapa, o professor registra de forma organizada, estruturada e em linguagem matemática os conceitos trabalhos através da resolução do problema. Formaliza as técnicas operatórias e as propriedades da disciplina.

Dessa forma, percebemos na RP um grande potencial enquanto Metodologia para o ensino de Cálculo Diferencial e Integral.

\section{MÉTODO}

Nossa pesquisa foi realizada durante o ano de 2019 em duas instituições de ensino superior, uma particular e a outra pública em Campos dos Goytacazes, RJ. As atividades foram realizadas com um total de 31 alunos do ciclo básico dos cursos de Engenharia de Produção, Engenharia Mecânica, e Engenharia de Computação oferecidos pelas instituições de ensino. A pesquisa foi submetida para avaliação na Plataforma Brasil, tendo sido os documentos aprovados pelo comitê de ética sob o número do parecer: 3.446.431, CAAE 14166519.2.0000.5244.

Os alunos participantes da pesquisa foram alocados em uma atividade extraclasse em horário alternativo às aulas dos seus respectivos cursos de graduação. O pesquisador foi o responsável pela condução das tarefas e atuou como professor e observador durante os encontros. As atividades aqui apresentadas foram realizadas uma em cada encontro, com duração aproximada de 2 horas nas instalações das próprias instituições. O horário da atividade foi definido segundo conveniência dos participantes e do pesquisador, que desempenhou o papel do professor durante as atividades.

Em cada encontro foi solicitado que fossem formados grupos de até 4 componentes. $\mathrm{O}$ pesquisador/professor utilizou em sala de aula a Metodologia de ensino de Resolução de Problemas, desenvolvida por George Polya seguindo no decorrer das atividades o já citado roteiro proposto por Ribeiro (2010).

Para elaboração das atividades o pesquisador escolheu três fontes principais, sendo os livros de CDI dos autores: Hoffmann e Bradley (2014), Stewart (2015) e Larson, Hostetler e Edwards (1998), a partir dos quais selecionou os problemas e os adaptou para aplicação segundo a Metodologia de Resolução de Problemas de Polya (2006) aos alunos. 


\subsection{PESQUISA QUALITATIVA}

Alguns fenômenos não podem ser totalmente compreendidos e expressos por números ou de forma estatística. Assim, a abordagem qualitativa funciona como um instrumento que busca assimilar e exprimir o que a pesquisa quantitativa, por vezes, não é capaz de apreender. Refere-se assim a captar significados, símbolos, conceitos, descrições e percepções dos fenômenos pelo ponto de vista dos indivíduos participantes da pesquisa. (BERG; LUNE, 2012).

Creswell (2014) afirma que a abordagem qualitativa possui caráter interpretativo e fornece uma visão naturalística do mundo. Este argumento se deve ao fato de o pesquisador necessitar de interpretar os significados que os participantes conferem aos fenômenos e por conta do estudo ser realizado não em laboratório, mas no ambiente em que os indivíduos vivem, trabalham ou onde se localiza o problema a ser estudado. $\mathrm{Na}$ investigação qualitativa, pesquisadores e participantes do estudo interagem e constroem juntos a pesquisa. As formas de coleta de dados são variadas e estão inclusas: entrevistas, questionários, análise de documentos, observações de campos, entre outras.

Nesse trabalho, considerando nosso objetivo, optamos por utilizar a abordagem qualitativa de investigação por entendermos que devido as suas caraterística trata-se do método de investigação mais adequado. Como meio de análise por entendermos que suas características envolvem a obtenção de dados descritivos obtidos no contato direto do pesquisador com a situação estudada, optamos pela análise qualitativa dos dados obtidos. Como forma de coleta de dados, utilizamos questionários com perguntas abertas.

\subsection{SITUAÇÕES-PROBLEMA}

O Quadro 1 apresenta os temas e conteúdos abordados em cada atividade, bem como as perguntas respondidas pelos estudantes ao final de cada encontro. Em seguida, no Quadro 2, são apresentadas as atividades elaboradas e aplicadas pelo pesquisador.

Quadro 1 - Conteúdo de Cálculo Diferencial e Integral trabalhados nas Atividades.

\begin{tabular}{|l|l|l|l|}
\hline Atividade & Temas & $\begin{array}{l}\text { Conteúdos de } \\
\text { Interesse }\end{array}$ & $\begin{array}{l}\text { Perguntas dos questionários } \\
\text { aplicados aos alunos }\end{array}$ \\
\hline Atividade I & $\begin{array}{l}\text { Funcionamento } \\
\text { de um Radar de } \\
\text { Trânsito - } \\
\text { Velocidade Média } \\
\text { e Velocidade } \\
\text { Instantânea; }\end{array}$ & $\begin{array}{l}\text { Taxa de variação; Taxa } \\
\text { instantânea de } \\
\text { variação, Taxa média de } \\
\text { variação; Definição de } \\
\text { derivada. }\end{array}$ & $\begin{array}{l}\text { "A compressão do assunto ou } \\
\text { conteúdo visto parece-Ihe } \\
\text { melhor com essa Metodologia?" } \\
\text { “Qual sua opinião sobre a } \\
\text { situação-problema apresentada } \\
\text { na Atividade I?" }\end{array}$ \\
& & \\
\hline
\end{tabular}




\section{Revista Thema}

\begin{tabular}{|c|c|c|c|}
\hline Atividade II & $\begin{array}{l}\text { Taxas de } \\
\text { Variação do } \\
\text { Espaço } \\
\text { Percorrido por } \\
\text { um Veículo e do } \\
\text { Lucro de uma } \\
\text { Empresa }\end{array}$ & $\begin{array}{l}\text { Derivada como Taxa de } \\
\text { variação; Significado do } \\
\text { Sinal da Derivada; } \\
\text { Função Crescente e } \\
\text { Decrescente; Derivadas } \\
\text { de Ordem Superior. }\end{array}$ & $\begin{array}{l}\text { "O que você acha de resolver } \\
\text { situações-problema em grupo?" } \\
\text { "Qual sua opinião sobre a } \\
\text { situação-problema apresentada } \\
\text { na Atividade II?" }\end{array}$ \\
\hline
\end{tabular}

Fonte: Elaborado pelos autores.

Quadro 2 - Atividades elaboradas pelo pesquisador.

\section{Atividades}

\section{Atividade I}

1 - O engenheiro de uma empresa ficou encarregado de monitorar e registrar o teste de um protótipo de radar de trânsito de longo alcance. Para analisar o funcionamento do equipamento, o engenheiro posicionou o radar de modo a monitorar verticalmente uma torre que possui 176 metros de altura. Do topo da torre foi solto um determinado objeto, deixado cair, até chegar ao solo. Antes do início do teste o mesmo levantou as seguintes informações:

Funcionamento do radar de trânsito:

Figura 1 - Como funciona um radar de trânsito.
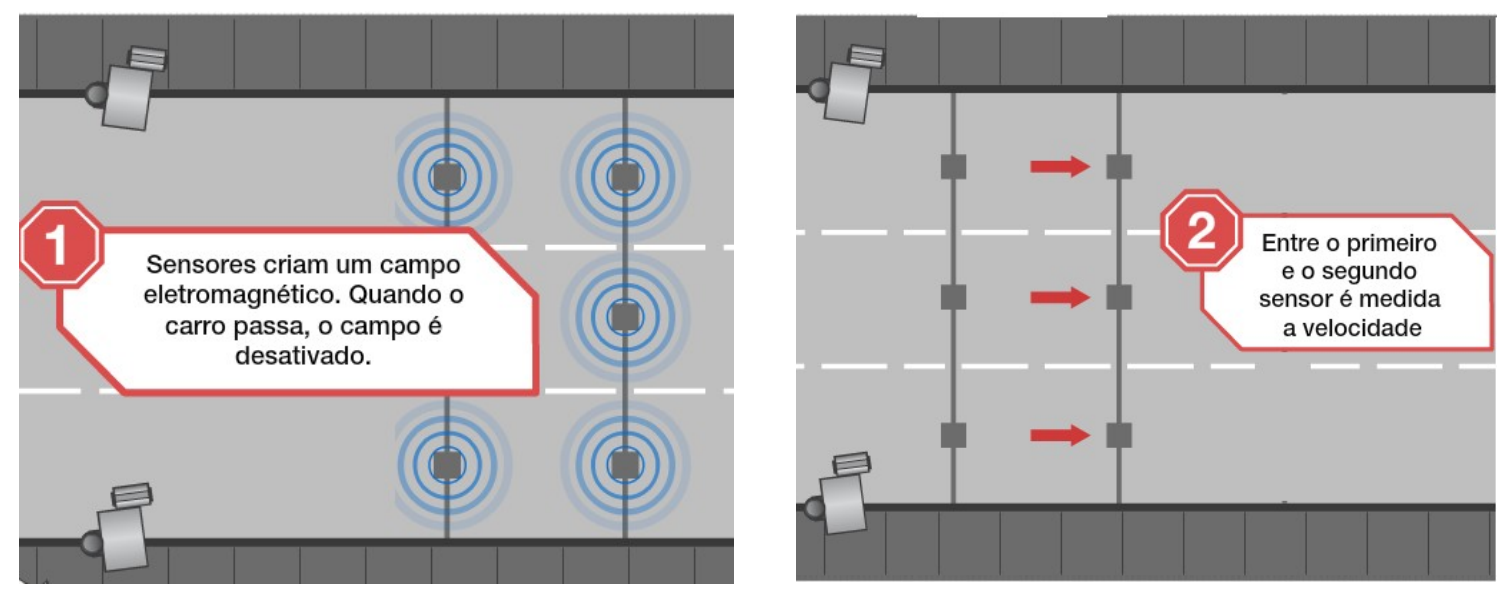

Fonte: Adaptado de NZN (2019).

Teste do radar de trânsito de longo alcance: 


\section{Revista Thema}

Figura 2 - Teste do protótipo de radar de trânsito.

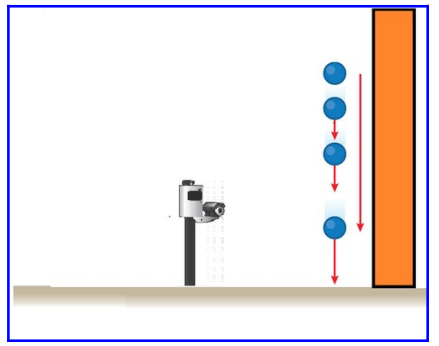

Fonte: Elaborado pelo Autor (2019).

Iniciando o teste no instante $\mathrm{t}=0$, o objeto começa a cair do topo da torre. Dado o tempo total de queda em, aproximadamente, 6 segundos e sendo a função do espaço percorrido pelo objeto em relação ao tempo (medido em segundos) como:

$f(t)=4,9 t^{2}$

A partir dessas informações, o sensor 1 do radar foi fixado no topo da torre, sendo considerado, nesse caso, a posição inicial $0 \mathrm{~m}$. O profissional precisa determinar quais as velocidades médias que serão registradas pelo radar se o sensor 2 for fixado nas seguintes posições:

a) $19,6 \mathrm{~m}$

b) $78,4 \mathrm{~m}$

c) $122 \mathrm{~m}$

Quais velocidades médias o radar irá registrar caso os sensores 1 e 2 forem instalados, respectivamente, nas posições correspondentes aos tempos:

d) $t=1$ e $t=4$

e) $t=2$ e $t=3$

f) $t=3$ e $t=5$

g) Após os testes, as velocidades registradas no equipamento foram coletadas e comparadas com as velocidades determinadas pelo profissional (letra "a", "b" e "c"). Entretanto, uma informação não foi correspondente. O radar quando posicionado com o sensor 1 no topo e o sensor 2 na posição correspondente a 5 segundos de queda registrou a velocidade de $49 \mathrm{~m} / \mathrm{s}$. Foi levantada a hipótese de que o radar por alguma falha em sua programação detectou a velocidade instantânea do objeto no determinado momento e não a velocidade média. Verifique se esta hipótese é uma suposição admissível.

h) Levando em consideração suas conclusões anteriores, explique de forma didática o que seria a velocidade instantânea e a velocidade média. 


\section{Atividade II}

1 - Um novo carro está sendo testado e foram requeridas algumas informações de seu teste. Após as primeiras t horas de uma viagem de 8 horas, o carro percorreu a distância segundo a função: $D(t)=64 t+10 t^{2} / 3-2 t^{3} / 9$ quilômetros.

a) Qual a distância percorrida e a velocidade instantânea do carro durante a sétima hora?

b) A que taxa a velocidade do carro está variando em relação ao tempo após 6 horas de viagem? O carro está acelerando ou desacelerando nesse determinado tempo?

c) É possível encontrar a taxa que a aceleração do carro está variando em relação ao tempo após 6 horas de viagem? Como você acha que poderia ser interpretado na prática essa variação?

2 - Determinada empresa fabrica somente em lotes de 1000 unidades cada. A produção atual é de 8000 unidades de certo produto por mês. No entanto, devido à nova demanda de um cliente, foi proposto que houvesse um acréscimo de 1 lote na produção do próximo mês. Para decidir quanto a atender ao pedido ou não, foi requisitado ao profissional responsável pelo setor uma análise da situação.

Foi identificada a seguinte relação entre a quantidade $x$, em milhares de unidades fabricadas do produto, e o lucro em reais:

$$
L(x)=-400 x^{2}+6800 x-12000
$$

a) Tendo essas informações, ele precisa identificar qual a taxa de variação do lucro em relação à quantidade de produção necessária para atender a nova demanda.

b) A taxa de variação encontrada para a nova demanda é positiva ou negativa? O que isso significa em relação ao comportamento do lucro em relação à produção nesta quantidade produzida?

c) Considerando a taxa de variação nessa quantidade específica, é válido que ele aceite a proposta para nova demanda? Justifique.

d) Para demonstrar que a partir de determinada quantidade produzida o lucro começa a decrescer, o responsável pelo setor convocou uma reunião com os gestores. Assim, como ele poderia demonstrar visualmente a relação do lucro com a quantidade produzida?

Fonte: Elaborado pelos autores.

\section{RESULTADOS}

Após a aplicação dos questionários aos alunos nos encontros, procedemos com a análise das respostas obtidas. Com os questionários pretendíamos coletar informações que respondessem de forma direta nossa pergunta de pesquisa sobre a contribuição da Metodologia RP para o ensino de Cálculo Diferencial e Integral, segundo o ponto de vista dos alunos. 


\section{Revista Thema}

V.17

A partir das respostas dos alunos e da observação do pesquisador/professor durante os encontros foi possível identificar benefícios da aplicação da Metodologia RP, proposta por G. Polya, para o ensino de CDI (Figura 3). A seguir apresentamos cada uma dessas contribuições constatadas e algumas respostas consideradas representativas para cada uma delas. Optamos por manter as transcrições originais conforme a grafia dos alunos.

Figura 3 - Benefícios da Metodologia de Resolução de Problemas constatados na pesquisa.

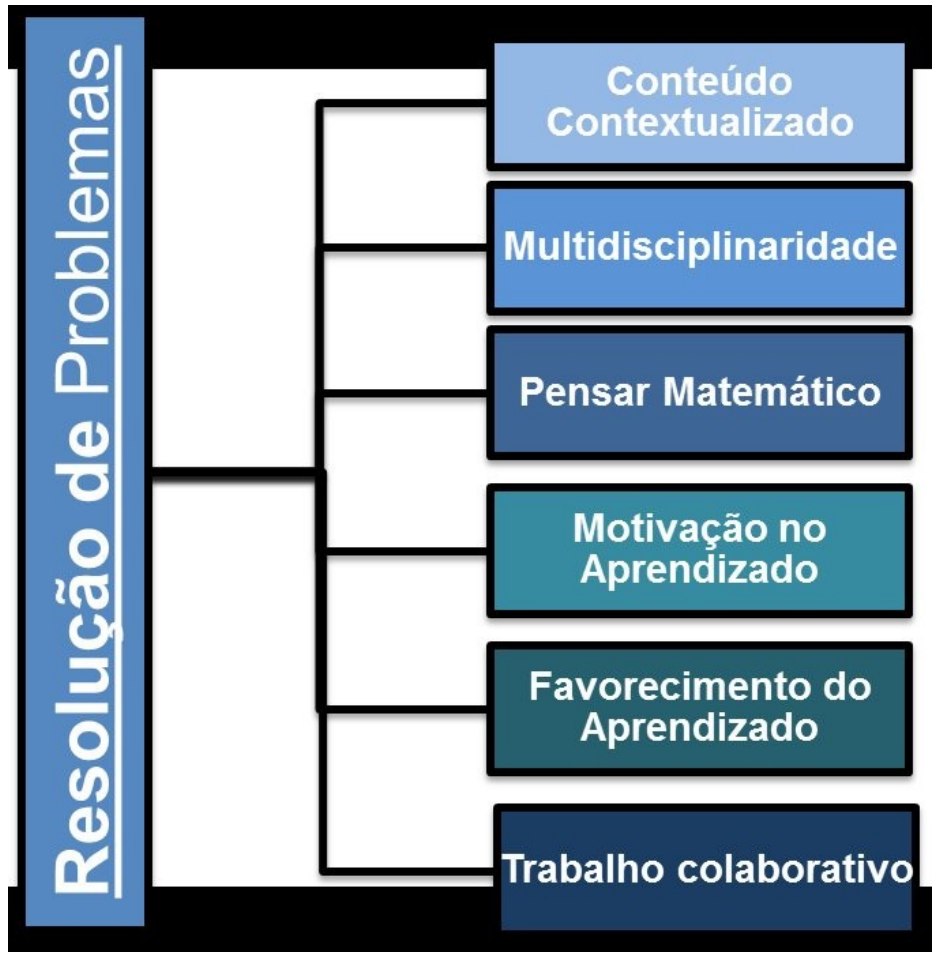

Fonte: Elaborada pelos autores.

Um dos aspectos positivos apresentados pela aplicação da RP foi a contextualização do conteúdo, por meio da qual os conceitos e teorias da disciplina passaram a fazer mais sentido para os alunos. Além disso, identificou-se a possibilidade de uma abordagem multidisciplinar do Cálculo, tendo em vista que através das situaçõesproblema é possível abordar mais de uma área do conhecimento de modo a promover um diálogo entre as diferentes disciplinas e seus conceitos. As seguintes respostas dos estudantes corroboram com essas percepções:

"Sim, pois cria todo um contexto que nos faz pensar para aplicar o que é aprendido durante as aulas normais."

"Sim, leva ao aluno a compreensão do porque da existência deste tipo de cálculo."

"Uma maneira contextualizada de abordar o assunto tornando a compreensão mais simples."

"É uma coisa que faz a gente refletir sobre como o calculo pode estar presente no nosso dia-a-dia."

"Achei bem legal por aproximar a área da física com o cálculo diferencial." 
"A situação-problema é interessante porque envolve não só problemas de Cálculo abstratos, mas também física."

"Achei interessante por abordar temas em que o cálculo possa ser aplicado (fora da matemática)."

Os aspectos da contextualização e da multidisciplinaridade na RP são oriundos do trabalho do professor em selecionar os problemas e adapta-los para construção de um novo conhecimento através da metodologia, como proposto por Polya (2006) e Ribeiro (2010). Dessa forma, faz-se necessário e de suma importância uma minuciosa pesquisa inicial do professor para elaboração de uma atividade que seja acessível e significativa para seus alunos.

Aliada à tarefa preliminar de seleção do problema gerador, ficou evidente que o comportamento do professor em sala de aula influencia de forma direta na aplicação da RP. A atuação do docente como mediador nos encontros, observando e incentivando na resolução dos problemas, concedeu aos alunos um papel ativo no processo de aprendizagem. Os participantes discutiram e avaliaram as próprias estratégias para resolver as situações-problema, desenvolvendo assim sua capacidade de pensar matematicamente. As seguintes respostas evidenciam esse aspecto da Metodologia RP:

"A abordagem é interessante porque desperta mais a curiosidade e faz o aluno pensar mais em vez de somente reproduzir o que foi dado."

"Foi apropriada, pois fez o grupo raciocinar sobre a diferença entre um valor e suas variações em determinado instante."

"Que abre sua visão a respeito do mundo e te faz questionar algumas áreas que você nunca pensou."

Em consonância com nossa constatação, Onuchic e Allevato (2011, p.82) afirmam: “Resolução de problemas desenvolve poder matemático nos alunos, ou seja, capacidade de pensar matematicamente, utilizar diferentes e convenientes estratégias em diferentes problemas, permitindo aumentar a compreensão dos conteúdos e conceitos matemáticos".

Outro beneficio da RP identificado em nossa análise foi a possibilidade de proporcionar aulas mais dinâmicas e agradáveis aos estudantes. Por meio da aplicação da Metodologia foi perceptível o interesse pelas atividades e a motivação presente no trabalho dos alunos. Os trechos a seguir corroboram com essa percepção:

"Mais competitivo e animador."

"Me parece legal e intrigante, porque a gente acaba criando teorias próprias."

"Mais divertido e produtivo."

"Acho interativa e mais interessante."

"Intrigante e desafiador. Fez com que a gente chegasse a uma busca interessante."

"Muito criativa e interessante de se resolver." 
A motivação apresentada pelos alunos está de acordo com as ideias defendidas por George Polya (1887 - 1985). O professor e matemático atribuiu à RP a capacidade de despertar a curiosidade e promover o engajamento dos estudantes no aprendizado dos conceitos da disciplina:

O problema pode ser modesto, mas se ele desafiar a curiosidade e puser em jogo as faculdades inventivas, quem o resolver por seus próprios meios experimentará a tensão e gozará o triunfo da descoberta. Experiências tais, numa idade susceptível, poderão gerar o gosto pelo trabalho mental e deixar, por toda sua vida, a sua marca na mente e no caráter. (POLYA, 2006, p.V).

Foi possível constatar também que a Metodologia proporcionou o favorecimento do aprendizado. A proposta de ensino foi identificada pelos alunos como sendo facilitadora da compreensão dos conteúdos da disciplina. Tal propriedade é atribuída por Onuchic e Allevato (2004) ao modo de trabalhar em sala de aula possibilitado pela Metodologia RP. Segundo os autores, a Resolução de Problemas de Polya faz com que o conteúdo ensinado passe a fazer mais sentido para os alunos, além de desenvolver sua capacidade de raciocínio e abstração. As seguintes respostas confirmam essa ideia:

"Sim, o assunto aqui, demonstrado dessa forma se mostrou mais claro e de maior entendimento."

"Bem mais esclarecedor e melhora o entendimento."

"Sim, ajudou a entender melhor o conceito de derivadas."

"Sim, pois se torna mais didático e facilita a visualização do assunto abordado."

Em consonância com nossa percepção, Noguti (2014) afirma, em sua pesquisa com alunos de cursos de Engenharia, que a aplicação da Metodologia RP tem a potencialidade de facilitar o aprendizado dos conceitos abordados nas aulas, além de refletir positivamente no interesse dos estudantes e na participação da classe. A autora relatou ainda, em seu trabalho, um aumento no desempenho e aprovação dos alunos.

Por último, um ponto marcante no trabalho foi que, indo além da formação de grupos, os alunos trabalharam de forma colaborativa nas atividades. Válido destacar que o importante atributo do trabalho colaborativo foi incorporado na Metodologia de ensino de Resolução de Problemas devido à influência das ideias de Lev Vygostky (18961934). Em sua teoria do sóciointeracionismo, Vygotsky ressalta a importância do outro para a aprendizagem, da troca de ideias e experiências e da interação social para o desenvolvimento intelectual. (VYGOTSKY, 2007; MOREIRA, 1999). Dessa forma, é possível perceber a importância do trabalho colaborativo em sala de aula levando em consideração a sua contribuição para o ensino-aprendizagem. Esse aspecto propiciado pelo trabalho com a RP pode ser notado nas seguintes respostas:

"Mais fácil, pois estamos sempre dividindo conhecimento e aprendendo coisas novas."

"Mais eficiente. Ouvir e debater ideias diferentes das minhas torna o aprendizado mais dinâmico e mais completo." 
"Trouxe vários tipos de resolução diferentes sendo bem interessante este compartilhamento e fazendo a gente pensar de formas diferentes."

Assim, com base na observação do pesquisador e nas respostas dos estudantes, constatou-se que os participantes puderam compartilhar conhecimentos e ideias sobre a disciplina, potencializando o seu aprendizado.

\section{CONSIDERAÇÕES FINAIS}

A partir dos resultados obtidos foi possível constatar as contribuições proporcionadas pela aplicação da Metodologia de ensino de Resolução de Problemas de Polya no ensino de Cálculo Diferencial e Integral. Os benefícios constatados foram:

Apresentação de um conteúdo contextualizado com os conceitos e teorias da disciplina, bem como a possibilidade de abordar mais de uma área do conhecimento, promovendo a multidisciplinaridade; Papel ativo do aluno na construção de seu conhecimento, desenvolvendo seu pensar matemático; Motivação no aprendizado pelo aumento do interesse dos discentes; Facilitação no aprendizado da disciplina por meio do método utilizado na RP e o trabalho colaborativo em sala de aula mediante o compartilhamento de conhecimentos e ideias entre os alunos.

Dessa forma, percebemos na Metodologia de ensino de Resolução de Problemas de Polya uma proposta pedagógica de grande potencial para promoção de um ensino significativo de Cálculo Diferencial e Integral. Diante de suas contribuições, sua relevância e aplicabilidade, a Resolução de Problemas apresenta-se como uma possível alternativa às práticas tradicionais, podendo ser empregada pelos educadores com o objetivo de conduzir os estudantes na construção de conhecimento em Cálculo Diferencial e Integral.

\section{AGRADECIMENTOS}

Nossos agradecimentos à Universidade Estadual do Norte Fluminense Darcy Ribeiro e ao Programa de Pós-Graduação em Ciências Naturais, responsáveis pela viabilização da pesquisa e pelo financiamento da mesma. Aos participantes e às instituições de ensino que abriram suas portas e permitiram a realização deste trabalho.

\section{REFERÊNCIAS}

\section{ABDELMALACK, Andrea. Ensino-Aprendizagem-Avaliação da Derivada para o} Curso de Engenharia Através da Resolução de Problemas. 2011. 175 f. Dissertação (Mestrado em Ensino de Ciências e Matemática) - Universidade Cruzeiro do Sul, São Paulo, 2011.

ARANHA, Elzo Alves; SANTOS, Paulo Henrique dos. Design thinking e habilidades empreendedoras na formação dos engenheiros de produção. In: ENCONTRO NACIONAL DE ENGENHARIA DE PRODUÇÃo, 36., 2016, João Pessoa. Anais... João Pessoa: Abepro, 2016. p.1-15.

BERG, Bruce L.; LUNE, Howard. Qualitative research methods: for the social sciences. 8. ed. California: Pearson, 2012. 
CRESWELL, JOHN W. Investigação qualitativa e projeto de pesquisa. 3. ed. Porto Alegre: Penso Editora, 2014.

FERREIRA, Luanne Lima; SILVA, Leonardo Brito da; NUNES, Célia Barros. O ensino da Matemática através da resolução de problemas no Curso de Engenharia Civil. In: ENCONTRO MINEIRO DE EDUCAÇÃO MATEMÁTICA, 7., 2015, Minas Gerais. Anais... Minas Gerais: Emem, 2015. p.1-12.

HOFFMANN, Laurence D.; BRADLEY, Gerald L. Cálculo: um curso moderno e suas aplicações. 10. ed. Rio de Janeiro: LTC, 2014.

INEP. ENADE 2014: relatório de área - Engenharia 2. 2016. Disponível em: <http://inep.gov.br/relatorios>. Acesso em: 24 out. 2018.

LARSON, Roland E.; HOSTETLER, Robert P.; EDWARDS, Bruce H. Cálculo com aplicações. 4. ed. Rio de Janeiro: LTC, 1998.

LOURENÇO, Márcia et al. Análise e proposta para diminuir a evasão em cálculo diferencial e integral. Tecnologia e Tendências, Novo Hamburgo, v.9, n.2, p.1-12, dez. 2014.

MOREIRA, Marco Antonio. Teorias de Aprendizagem. São Paulo: Pedagógica e Universitária Ltda., 1999.

NOGUTI, Fabiane Cristina Höpner. Um curso de Matemática básica através da resolução de problemas para alunos ingressantes da Universidade Federal do Pampa, campus Alegrete. 2014. 370 f. Tese (Programa de Pós-graduação em Matemática) - Universidade Estadual Paulista, Rio Claro, 2014.

NZN. Como funcionam os radares de trânsito [infográfico]. Disponível em: $<$ https://www.tecmundo.com.br/infografico/10350-como-funcionam-os-radares-detransito-infografico-.htm>. Acesso em: 3 maio 2019.

ONUCHIC, L. R.; ALLEVATO, N. S. G. Novas reflexões sobre o ensino-aprendizagem de matemática através da resolução de problemas. In: BICUDO, M. A. V.; BORBA, M. C. (Orgs.). Educação Matemática: pesquisa em movimento. São Paulo: Cortez, 2004. p.213-231.

ONUCHIC, Lourdes de La Rosa; ALLEVATO, Norma Suely Gomes. Pesquisa em resolução de problemas: caminhos, avanços e novas perspectivas. Bolema, Rio Claro, v.25, n.41, p.73-98, dez. 2011.

PAULA, Marilia Rios de; SOARES, Gisele Americo; DIAS, Rubens Alves. Uma experiência nas aulas de cálculo da Engenharia: produção de videoaulas e avaliação por pares. International Journal On Active Learning, v.1, n.1, p.78-88, 12 dez. 2016.

PINTO, Rieuse Lopes; LIMA, Gabriel Loureiro de. Ensino de equações diferenciais ordinárias em cursos de Engenharia Mecânica. Revista de Produção Discente em Educação Matemática, São Paulo, v.6, n.2, p.18-29, 2017.

POLYA, G. How to solve It: a new aspect of mathematical method. Princeton: Princeton University Press, 1945.

POLYA, G. A arte de resolver problemas. Rio de Janeiro: Interciência, 2006. 


\section{Revista Thema}

\begin{tabular}{l|l|l} 
v.17 & n.2 & 2020
\end{tabular}

RIBEIRO, Marcos Vinícius. O ensino do conceito de integral, em sala de aula, com recursos da história da Matemática e da resolução de problemas. 2010. 324 f. Dissertação (Mestrado em Educação Matemática) - Universidade Estadual Paulista, Rio Claro, 2010.

SOUZA, Débora Vieira de; FONSECA, Rogério Ferreira da. Reflexões acerca da aprendizagem baseada em problemas na abordagem de noções de cálculo diferencial e integral. Educação Matemática Pesquisa: Revista do Programa de Estudos PósGraduados em Educação Matemática, v.19, n.1, p.197-221, 2017.

STARON, Francielly. O monstro da reprovação em cálculo diferencial integral. In: CONEX, 14., 2016, Ponta Grossa. Anais... Ponta Grossa: Conex, 2016. p.1-7.

STEWART, J. Cálculo. 7.ed. São Paulo: Pioneira Thomsom Learning, 2015.

VYGOTSKY, L. S. A formação social da mente. 7. ed. São Paulo: Martins Fontes, 2007.

WATANABE, Flávio Y. et al. A aprendizagem baseada em equipes e o desenvolvimento de habilidades transversais. In: CONGRESSO BRASILEIRO DE EDUCAÇÃO EM

ENGENHARIA, 46., 2018, Salvador. Anais... Salvador: Abenge, 2018. p.1-10. 